\title{
O USO VARIÁVEL DE [-STE] NA PÁGINA TAL QUAL DUBLAGENS E A CONSTRUÇÃO DE IDENTIDADE SOCIAL
}

\author{
THE VARIABLE USE OF [-STE] ON THE TAL QUAL DUBLAGENS PAGE \\ AND THE CONSTRUCTION OF SOCIAL IDENTITY
}

\author{
Kamilla Oliveira do Amaral | Lattes | amaralkamilla17@gmail.com \\ Universidade Federal de Santa Catarina
}

Resumo: O presente estudo tem como objetivo analisar a realização variável de [-STE] na página do Instagram Tal Qual Dublagens - constituída principalmente por curtos vídeos de dublagens produzidos pelo comediante Gustavo Libório -, verificando a existência de significados socioidentitários indexicalizados pelo referido morfema. Para esta pesquisa, observamos a dinâmica interacional da Tal Qual Dublagens, que interpretamos como uma comunidade de práticas (ECKERT, 2006), e analisamos 302 ocorrências de [-STE], mapeadas durante a etnografia virtual (HINE, 2000) realizada na página. A partir da análise verificamos que [-STE] conta com cinco formas alternativas que estão relacionadas a alterações morfofonéticas. São elas: -ste, -stes, -stis, -rte e -rtes. Cada uma das cinco formas indexicaliza concomitantemente diferentes instâncias de significação: uma referente ao significado semântico-pragmático do morfema (expressão de segunda pessoa do singular) e a outra ao significado social, que carrega valores identitários e ideológicos dos sujeitos da referida comunidade. Este significado se distribui em diferentes camadas: uma relacionada a macrocategorias e outra a relações de grupo (seja de grupo regional, de grupo gay, ou de grupo social, como a CP Tal Qual Dublagens).

Palavras-Chave: Variação. Significado social. Identidade.

\begin{abstract}
The present study aims to analyze the variable realizations of [-STE] in the Instagram webpage Tal Qual Dublagens, verifying the existence of social identity meanings indexed by the referred morpheme. For this research we have observed the interactional dynamics of the page, which we interpret as a community of practice (ECKERT, 2006), and analyzed 302 occurrences of [-STE], mapped during the virtual ethnography (HINE, 2000) carried out on the page. From the analysis we verified that [-STE] has five alternative forms that are related to morphological alterations: -ste, -stes, -stis, -rte and -rtes. Each one of the five forms indexes concomitantly four different layers of meaning: one re-
\end{abstract}


ferring to the referential meaning of morpheme (second person singular expression) and three associated to socioidentitarian meanings, including meaning of macrossociological identity; of regional identity and of gay identity. The simultaneous action of these four layers expresses a notion of plural identity, called social group identity.

Keywords: Variation. Socioidentitarian meanings. Social group identity.

\section{Iniciando a discussão}

As transformações socioeconômicas e culturais desencadeadas pelo fenômeno da globalização ${ }^{1}$, o qual introduz a era da Pós-Modernidade, trazem à tona uma nova configuração de sociedade, na qual noções de estabilidade, homogeneidade, coerência, fixidez e unicidade não são mais tomadas como aspectos constituintes dos sujeitos e das suas relações sociais (HALL, 2006).

Tais transformações têm gerado grandes impactos no campo da Sociolinguística - mais especificamente a Sociolinguística Variacionista (SV) - e alterado significativamente a maneira como os estudos sobre a relação entre e língua e sociedade vêm sendo desenvolvidos. Para lidar com cenários completamente novos e diversificados com os quais os sujeitos podem se relacionar, o escopo do que vem sendo entendido como o objeto e o locus de estudo da SV neste tempo e espaço em que estamos imersos precisam ser reconsiderados e redefinidos.

Tendo isso em vista, Eckert $(2000,2005)$ propõe (re)pensarmos a heterogeneidade linguística e, com esse remodelamento, a variação - muito além de ser um processo pelo qual duas ou mais formas podem ocorrer no mesmo contexto linguístico com o mesmo valor referencial (ou o mesmo valor de verdade) e com o mesmo significado (TARALLO, 1986) - passa a ser entendida como parte de um sistema sociossemiótico, capaz de indiciar que interesses e objetivos estão por detrás dos usos linguísticos dos sujeitos (ECKERT, 2012).

Como esses interesses são continuamente alterados a depender da situação comunicativa e dos diferentes papéis sociais desempenhados por esses indivíduos, o foco em comunidades linguísticas relativamente estáveis e homogêneas - comunidades de fala -, como locus de análise para a explicação da variação e mudança linguística, passa a ser redirecionado para questões que emergem de dinâmicas interacionais presentes em comunidades mais locais e menos globais.

\footnotetext{
${ }^{1}$ Hall (2006, p. 67) evoca Anthony McGrew para definir globalização como “[...] aqueles processos, atuantes numa escala global que atravessam fronteiras nacionais, integrando e conectando comunidades e organizações em novas combinações de espaço-tempo, tornando o mundo, em realidade e em experiência, mais interconectado [...]."
} 
A partir desse redimensionamento, aspectos de natureza estilística, que geralmente são secundarizados na análise variacionista de perspectiva laboviana, são deslocados das margens para o centro, tornando-se um dos principais interesses da SV nesse novo cenário sociocultural (COUPLAND, 2011). Diante desse novo olhar para o estilo e para o significado social, a noção de variação é ampliada, o que significa que ela deixa de ser assumida somente como um reflexo da influência de fatores sociais em nível macro (como sexo/gênero, faixa etária, escolaridade, nível socioeconômico, raça/etnia), passando a ser entendida também como uma ferramenta através da qual os sujeitos podem construir e reconstruir suas identidades sociais.

Baseado nessas perspectivas, o objetivo central deste estudo é discutir questões estilístico-identitárias envolvidas na realização de fenômenos linguísticos variáveis. E para elucidar tal discussão, analisamos o uso de $[-\mathrm{STE}]^{2}$ em uma comunidade de práticas, que se estabelece na dimensão online ${ }^{3}$, a página Tal Qual Dublagens.

A Tal Qual Dublagens é uma página da Internet criada pelo manauara Gustavo Libório e surge primeiramente como canal no Youtube, em 2011, e depois é expandida para as demais redes sociais, como o Facebook (no mesmo ano) e posteriormente o Instagram (em 2013). Os principais conteúdos produzidos por Gustavo são as dublagens de vídeos, publicadas em seu canal, e as postagens nas redes sociais da página.

Nos primeiros anos de criação da Tal Qual Dublagens, Gustavo produzia as dublagens tendo em vista um público específico: a comunidade GLS (termo que era utilizado na época) e os amazonenses, mais especificamente os manauaras. No entanto, à medida que o território on-line da página foi expandido, através da presença da Tal Qual Dublagens em outras plataformas virtuais, esse público alvo inicial também foi ampliado, trazendo cada vez mais seguidores de perfis diversos e heterogêneos.

Ainda que Gustavo lide com uma diversidade de pessoas, com naturalidades, nacionalidades, raças, sexos, gêneros, idades, classes socioeconômicas, graus de escolaridade, personalidades e identidades diversas, ele faz questão de usar uma linguagem que reflete seus próprios traços linguísticos de identificação social, como por exemplo, o uso de algumas expressões consideradas típicas do amazonense (já mesmo, até o tucupi, até o talo) haja vista sua naturalidade manauara, e algumas expressões do dialeto bajubá/pajubá (fazer a chuca, viado, boy), considerando sua orientação sexual (homossexual autode-

\footnotetext{
${ }^{2}$ Ao longo deste texto, quando o item "STE" estiver entre colchetes ([ ] ), significa que o segmento corresponde a uma macroforma que engloba formas alternativas de realização, estando estas notadas em minúsculo e em itálico.

${ }^{3}$ Neste artigo não pretendemos nos deter nessa discussão. Para um aprofundamento detalhado dessa questão, remetemos o leitor à dissertação de Amaral (2020b).
} 
clarado). E mesmo que nem todos seus seguidores compartilhem exatamente os mesmos traços socioculturais, por exemplo, tendo em vista que há uma parcela significativa de pessoas provenientes de outras regiões do Brasil e até de outros países, em alguma medida, eles parecem estabelecer uma relação de identificação com a página em um nível mais subjetivo e ideológico.

Considerando que a Tal Qual Dublagens está presente em vários Sites de Redes Sociais (SRS), o alcance da página é bastante abrangente e, se somarmos a quantidade de inscritos no canal no Youtube e a de seguidores no Facebook e no Instagram - que chega a pouco mais de 1 milhão de seguidores -, é possível dizer que a Tal Qual Dublagens configura uma comunidade com um alcance global. Para esta pesquisa, decidimos investigar somente uma parte dessa grande comunidade e para isso escolhemos o Instagram da página. Este estudo se refere a uma pesquisa quali-quantitativa que segue uma orientação etnográfica, mais especificamente ao que se tem denominado Etnografia Virtual, nos termos de Christine Hine (2000). Por aproximadamente dois anos, observamos as dinâmicas interacionais da página Tal Qual Dublagens no Instagram e mapeamos todas as ocorrências de [-STE] realizadas nos anos de 2013, 2014, 2015 e 2018.

A amostra analisada neste estudo trata de um recorte de uma amostra mais ampla, utilizada na pesquisa de Amaral (2020a, 2020b ${ }^{4}$ ), que contém 1.049 ocorrências de [-STE]. Essas ocorrências referem-se a dados escritos gerados de posts e comentários realizados tanto por Gustavo, na figura da "titia Tal Qual” - personagem criada para a interação com o público - quanto por seus seguidores, e estão distribuídas em quatro diferentes contextos linguísticos de uso: (i) base verbal padrão ${ }^{5}$, cuja configuração gramatical é sujeito P2 (tu) + verbo no Pretérito Perfeito do Indicativo (PP), em que [-STE] corresponde à desinência número-pessoal (DNP) privativa ao PP e concorda necessariamente com P2 (tu), como em (1), (2) e (3); (ii) base verbal não padrão - caracterizado pela ausência dos traços gramaticais que configuram o uso canônico do item (relacionados à pessoa do discurso, tempo e modo verbal e função sintática), como em (4), (5) e (6); (iii) base não verbal - que corresponde ao emprego de [-STE] preso a outras classes de

\footnotetext{
${ }^{4} \mathrm{Na}$ dissertação de Amaral (2020b), foram analisados 12 grupos de fatores potencialmente correlacionados com o funcionamento e uso variável de [-STE]: cinco de ordem gramatical, sobretudo de natureza morfossintática e semântico-pragmática (tipo de base, pessoa do discurso, função sintática de P2, tempo e modo da base verbal e categoria morfológica de [-STE]); dois de natureza linguística (categoria gramatical da base não verbal e item lexical); e cinco de natureza extralinguística (origem do dado, gatilho, conteúdo do post, natureza do comentário e data de publicação).

${ }^{5} \mathrm{O}$ contexto de base verbal padrão não deve ser confundido com norma-padrão. Corresponde tão somente à configuração prototípica da forma verbal canônica de P2, em que [-STE] e suas diferentes formas de realização codificam a desinência número-pessoal privativa de PP.
} 
palavras que não o verbo, como em (7), (8) e (9) -; e (iv) palavras de origem estrangeira, como em (10), (11) e (12).

Quadro 1. Dados ilustrativos dos contextos linguísticos de uso de [-STE]

\begin{tabular}{|c|c|c|c|}
\hline Base Verbal Padrão & $\begin{array}{l}\text { Base Verbal Não } \\
\text { Padrão }\end{array}$ & Base Não Verbal & $\begin{array}{l}\text { Palavras de origem } \\
\text { estrangeira }\end{array}$ \\
\hline $\begin{array}{l}\text { (1) Mana, tu arrasaste } \\
\text { (2) Farrétempo que } \\
\text { queria vestes e arrasastes } \\
\text { (3) botartes a cara no } \\
\text { sol mesmo né cachorra } \\
\text { leprosenta? Lindo! }\end{array}$ & $\begin{array}{l}\text { (5) Eu já compreistes } \\
\text { o meu fuleira!!!! [...] ... } \\
\text { Traaaaahhhh } \\
\text { (6) [...] tô com ódio, vou } \\
\text { esculhambartes![...] }\end{array}$ & $\begin{array}{l}\text { (7) piseistes no bodortes } \\
\text { pelo amor de deustis }[\ldots] \\
\text { (8) Cadeeestes } \\
\text { demoniia!?!? [...] } \\
\text { (9) [...] hazourtesss. } \\
\text { O sonho dela devia } \\
\text { ser dançarinartes da } \\
\text { Joelmartes }\end{array}$ & $\begin{array}{l}\text { (10) Okeste bb } \\
\text { (11) Manaa acho que } \\
\text { tey boystes já terminou o } \\
\text { serviço! [...] } \\
\text { (12) Enquanto a nova } \\
\text { temporada não começa, } \\
\text { vamos relembrar a } \\
\text { @anapaularenault } \\
\text { enkaralhando no } \\
\text { BBBêrtes. Vamos marcá- } \\
\text { la pra ela ver??? }\end{array}$ \\
\hline
\end{tabular}

Fonte: Amaral (2020a, p. 172).

Para esta pesquisa, delimitamos a análise do uso variável de [-STE] somente aos dados da base verbal padrão. ${ }^{6}$ Nosso interesse é verificar que significados são indexicalizados pelas formas alternativas de [-STE] e em que medida a expressão desses significados pode estar correlacionada com a construção de identidade social da comunidade.

Sendo assim, o artigo está estruturado da seguinte forma: esta introdução (Seção 1) é seguida pelo referencial teórico mobilizado (Seção 2); pela descrição da comunidade em análise (Seção 3); pela análise e discussão dos resultados (Seção 4), e pelas considerações finais.

\section{Sociolinguística Variacionista e as novas perspectivas de estilo e identidade}

A variação estilística sempre esteve presente nos estudos de Sociolinguística Variacionista, entretanto a concepção de estilo em cada um desses estudos é o que define se ele será tratado como o foco, ou como um recurso secundário.

Na perspectiva laboviana, o "grau de atenção à fala” (LABOV, 2008 [1972]) é central para definir a variação estilística. Contudo, ao circunscrever o estilo nessa abordagem, aspectos interacionais e identitários, por exemplo, são deixados de lado. Essa lacuna acabou abrindo espaço para a emergência de novas perspectivas teórico-metodológicas sobre o estilo e sobre o significado social.

Com o objetivo de diferenciar e sistematizar os estudos desenvolvidos sob essas novas abordagens, Eckert $(2005,2012,2016)$ propõe um agrupamento deles em três fases distintas - ainda que não sejam sucessivas. Essas três fases são denominadas como 
ondas da SV, as quais são brevemente apresentadas a seguir. Damos um maior enfoque à perspectiva de terceira onda, em que abordamos conceitos como indexicalidade, ordem indexical e identidade, por exemplo, que são centrais para o desenvolvimento da nossa análise.

\subsection{As ondas da SV}

A primeira onda está fortemente relacionada aos estudos labovianos e é inaugurada com a tese de doutorado de Labov (1966) sobre a estratificação social do /r/ pré-vocálico e pós-vocálico na cidade de Nova York. Nessa tendência, a uniformidade com que os padrões estilísticos atravessam a hierarquia socioeconômica sugere um consenso sobre o significado das variáveis que se dá através da observação de padrões nas comunidades de fala.

Considerando isso, o significado social da variação é baseado nas categorias que serviram para selecionar e classificar os falantes e não no conhecimento direto dos próprios sujeitos e suas comunidades. Nesse sentido, as atividades linguísticas dos falantes parecem induzir a uma interpretação que estabelece, por um lado, valor de prestígio associado à fala de indivíduos de classes mais altas economicamente e, por outro, de estigma associado à fala dos de classes inferiores - valores esses correlacionados diretamente ao grau de monitoramento da fala, responsável, na visão laboviana, pela variação estilística.

Já a segunda onda é marcada, sobretudo, por uma mudança de natureza metodológica. Nesse sentido, os estudos dessa tendência utilizam métodos etnográficos para verificar como categorias macrossociais estão correlacionadas com os usos variáveis dos falantes (ECKERT, 2012). Nessa tendência, ainda que o foco continue sendo categorias estáticas - como sexo, idade e grau de escolaridade, por exemplo -, o locus de análise da variação passa a ser redirecionado para comunidades menores, como as redes sociais ${ }^{7}$ ou as comunidades de práticas ${ }^{8}$. Ao assumir que a variação está situada nessas comunidades, é possível estabelecer que o valor social da variação está fortemente relacionado a dinâmicas sociais mais locais e menos globais, o que corrobora para o fornecimento de um retrato local das variáveis linguísticas (ECKERT, 2012).

Tendo isso em vista, os estudos de segunda onda passam a considerar um leque mais amplo de significados para as variantes e, nesse movimento, apresentam uma no-

\footnotetext{
${ }^{7}$ Redes de relacionamento dos indivíduos estabelecidas na vida cotidiana e que geralmente envolvem relações de graus de parentesco, amizade, ocupação (ambiente de trabalho) etc. (MILROY, 1980, 2002)

${ }^{8}$ Uma comunidade de práticas corresponde a um grupo de pessoas que compartilham, entre outros, comportamentos, pontos de vistas, opiniões, valores e preceitos, relações de poder, formas de se comunicar (ECKERT, 2006).
} 
ção de variação estilística mais ampliada, em que a maneira como os indivíduos usam as variantes para transmitir uma variedade de afiliações, características e posturas tanto no grupo/comunidade local como em interações locais importa para explicar a relação entre língua e sociedade (SCHILLING, 2013).

Na terceira onda, a noção de estilo abarca questões ainda mais amplas que na segunda onda. Nesse sentido, o estilo passa a ser entendido como um "fenômeno multinível - uma configuração coordenada de características linguísticas, projetada e interpretada holisticamente" (COUPLAND, 2011, p. 140) e a prática estilística ${ }^{10}$ se torna fundamental para compreender a variação e mudança.

O empreendimento variacionista de terceira onda tem interesse (i) nos significados sociais da variação, considerando que as variáveis linguísticas não estão somente associadas às categorias sociais, mas principalmente às posturas (stances) e características dos sujeitos que constituem essas categorias e (ii) na contínua variação/mudança desses significados sociais, tendo em vista que nem a língua, nem os sujeitos que a usam e criam sentidos para esses usos devem ser tomados como fixos e imutáveis.

Considerando que os significados sociais das práticas estilísticas dos falantes emergem como produto do princípio semiótico da diferenciação linguística, que circunscreve a relação entre signos icônicos, indiciais e simbólicos (PEIRCE, 1932 apud IRVINE; GAL, 2000), outro interesse desta tendência está na propriedade indicial dos signos, mais especificamente no que se refere à noção de indexicalidade.

\subsection{Indexicalidade}

Para Silverstein (2009), a indexicalidade é revelada no modo como, gradativamente, os signos linguísticos refletem a relação entre os usuários desses signos e os contextos específicos nos quais esses signos são usados. São os significados indexicais presentes na língua que nos permitem fazer correlações entre o que é dito e as características de quem disse. Através disso passamos a fazer julgamento de caráter e rotular as pessoas a partir da forma com que elas se comunicam com o mundo social.

Nesse cenário, as diferentes formas de usar a língua dizem muito sobre como estruturas microssociais podem estar relacionadas às macrossociais e, para lidar com isso, o

\footnotetext{
9 As traduções ao longo do texto são livres e de responsabilidade nossa. No original: "Style is in fact a multi-level phenomenon - a coordinated configuration of linguistic features, designed and interpreted holistically."

${ }^{10}$ Para Eckert (2008, p. 456), “práticas estilísticas são tanto o processo de interpretação, quanto de produção de estilos, tendo em vista que ambos acontecem constante e iterativamente”. No original: "By stylistic practice, I mean both the interpretation and the production of styles, for the two take places constantly and iteratively."
} 
conceito de ordem indexical é central.

Para Silverstein (2003), a atribuição de significados aos signos indexicais está sujeita a uma certa adequação desses signos aos contextos em que podem ser usados. Esse constante processo de vinculação contextual na indexicalização reflete a forma com que os sujeitos culturalmente interpretam a relação dialética entre significados mais globais e mais locais, que estão relacionados com as macro e microformas de identificação social. Essa interpretação é sempre um processo não arbitrário, motivada pelos graus de engajamento ideológico que os sujeitos manifestam em relação ao uso da ordem indexical, o que o autor denomina como etno-metapragmática desse uso. Dentro dessa perspectiva, a ordem indexical é entendida como uma realização performática, de uma estrutura já constituída de valor semiótico (SILVERSTEIN, 2003).

Diante disso, cada vez que um signo é reinterpretado, seus significados refletem um matiz ideológico cada vez mais complexo, o que significa que há um acréscimo de significado social para o signo, e ele adquire, portanto, um novo valor ou um novo ordenamento indexical. Eckert $(2008,2018)$ argumenta que embora a noção de ordenação indexical pareça implicar em uma linearidade quanto aos significados sociais dos signos, esse não é o objetivo de Silverstein (2003). Nesse sentido, tendo em vista que os significados sociais expressos pelas variáveis não são estanques, a ordem indexical dos signos também não pode ser vista como tal.

Precisamente porque os processos de reinterpretação dos signos, que geram novos significados a eles, "ocorrem dentro de um campo ideológico fluido e em constante mudança"11 (SILVERSTEIN, 2003 apud ECKERT, 2018, p. 154), a ordem indexical pode se dar simultaneamente e ao longo do tempo em múltiplas direções, estabelecendo um conjunto de significados correlacionados, os quais, em dado momento, constituem o que Eckert denomina como campo indexical - "constelação de significados ideologicamente relacionados, os quais podem ser ativados nas situações de uso das variáveis" (ECKERT, 2008, p. 454) $)^{12}$.

É importante destacar ainda que os recursos linguísticos que decidimos usar nas situações comunicativas são formas de autorrepresentação social, o que implica dizer que essas escolhas não podem ser vistas como naturais ou arbitrárias, pelo contrário, elas são ideologicamente motivadas pelos interesses e pelas posições sociais que os sujeitos ocupam no ato comunicativo e no mundo social (BLOMMAERT, 2005).

\footnotetext{
${ }^{11}$ No original: "[... ] they take place within a fluid and ever- changing ideological field."

${ }^{12}$ No original: "[...] constellation of ideologically related meanings, any one of which can be activated in the situated use of the variable."
} 
Esse trabalho de representação ou autocategorização através da língua parece configurar um processo pelo qual "os falantes, como agentes no espaço social (e sociolinguístico), negociam suas posições e objetivos dentro de um sistema de distinções e possibilidades" (IRVINE, 2001, p. 23-24) e "invocam significados na forma de expectativas em relação aos outros e ao próprio comportamento de alguém" (STETS; BURKE, 2000, p. 225). E esse cenário é apontado por Stets e Burke (2000) como a base da formação de identidade dos sujeitos, conceito que discutimos a seguir.

\subsection{Identidade}

Hall (2006) argumenta que as concepções de identidade estão intimamente relacionadas às transformações histórico-culturais pelas quais os sujeitos têm sido atravessados ao longo do tempo. A primeira delas, o Iluminismo, gera um tipo de sujeito fechado em si mesmo, contínuo e idêntico a ele mesmo, o que desencadeia um entendimento de identidade como essencial, fundamental e individual. O segundo evento apontado por Hall é a Modernidade, que traz consigo o sujeito sociológico. Esse tipo de sujeito, diferentemente do anterior, passa a se entender como um indivíduo que pertence a algo mais amplo, um sujeito que se relaciona com outras pessoas. A partir dessa relação, sua identidade, que ainda está associada a uma essência interior, pode ser "modificada num diálogo contínuo com os mundos culturais 'exteriores"' (HALL, 2006, p. 11), suscitando uma concepção de identidade como um fenômeno de autocompreensão interativa, coletiva, uma identidade cultural.

Com a Pós-Modernidade, a terceira transformação apontada por Hall, a ideia de identidade como "plenamente unificada, completa, segura e coerente" (HALL, 2006, p. 13), é substituída por uma noção de incoerência e contradição, uma vez que ela não é fixa, não é essencial, muito menos homogênea, não é predeterminada biologicamente e sim historicamente e está em contínuo processo de construção. Essa concepção de identidade está alinhada a um tipo de sujeito global(izado) que é deslocado, desterritorializado, fragmentado e múltiplo. E é esse tipo de sujeito e essa concepção de identidade que a terceira onda busca para compreender a variação linguística e os significados sociais da variação.

Diferentemente da primeira e segunda ondas da SV, em que a identidade desempenha funções de identificação e categorização, estabelecendo distinções entre macrocategorias a partir das quais há um posicionamento do eu perante o outro (primeira onda); e reflete marcas de subjetividade na relação estável entre a autocompreensão de si e o lugar social (segunda onda); na terceira onda, a identidade está associada a um alinhamento 
que ocorre sobretudo a partir da relação entre o indivíduo e os grupos em que está inserido e na relação entre os graus de afiliação e pertencimento a esses grupos (BRUBAKER; COOPER, 2000).

Considerando isso, a definição de Kiesling (2013) parece se alinhar bastante com o entendimento que buscamos assumir neste estudo. Para o autor, "identidade é como os indivíduos se definem, se criam ou pensam sobre si mesmos em termos de suas relações com outros indivíduos e grupos ainda que sejam reais ou imaginados" (KIESLING, 2013, p. 450, grifo no original $)^{13}$. Essa definição nos interessa porque parece (i) deslocar o foco de indivíduos estáticos para o processo de como os falantes usam a língua para criar relações; (ii) capta a natureza dual individual e social da identidade, o que coaduna com a discussão de que as identidades não são definidas e determinadas a priori, mas podem ser construídas em meio a outros processos semióticos e ideológicos.

É importante destacar também que cada contexto define o tipo de interação envolvida entre locutor-interlocutor e parece induzir esses sujeitos a tomar certas posturas (stances) e construir personae por meio de práticas estilísticas fortemente entretecidas por componentes ideológicos.

A postura é uma propriedade que emerge da interação e, por isso, não é algo que é facilmente identificado sem olharmos para a própria situação de interação ou os contextos sociais e históricos relacionados. As posturas dos falantes são performances através das quais eles podem se alinhar ou se desalinhar e/ou ironizar associações estereotípicas com formas linguísticas particulares (JAFFE, 2009). Essas posturas podem, assim, expressar significados múltiplos ou ambíguos. Isso torna a postura um ponto crucial de entrada em análises que focalizam as maneiras complexas pelas quais os falantes gerenciam múltiplas identidades (ou múltiplos aspectos da identidade) através dos diferentes estilos que escolhem 'usar' na interação.

Escolher um estilo em uma situação comunicativa de interação é eleger, considerando um número de possibilidades distintas, que máscara social (JUNG, 1975) usar em cada contexto. Essas escolhas estilísticas configuram-se como um processo contínuo e agentivo, em que a agentividade é concedida tanto ao falante quanto ao ouvinte, haja vista que é na relação locutor-interlocutor, ou na autorrepresentação do eu perante o outro, que os estilos e os significados são construídos e reconstruídos.

É através dos movimentos estilísticos dos sujeitos que as personae - que corresponde a parte de um processo no qual os sujeitos performam maneiras de se mostrar para o outro através de máscaras sociais (JUNG, 1975) - são construídas. Tendo isso em vista,

${ }^{13}$ No original: "identity is how individuals define, create themselves in terms of their relationships with other individuals and groups, whether these others are real or imagined." 
as personae não podem ser vistas nem como estáticas, muito menos como pré-determinadas. Elas são construídas e reconstruídas a todo momento, sobretudo quando o sujeito se depara frente a demandas e convenções socialmente estabelecidas. Para Kiesling (2013), essas personae, junto com categorias de censo, papéis institucionais, posturas e características interferem no processo de construção das identidades porque estão interconectadas, configurando um processo em multicamadas e multiníveis. Esses variados níveis de identidade se conectam através da variação, momento em que se tornam alinhadas em ideologias semióticas mais amplas que multiplicam seus efeitos.

Por tudo isso, entendemos que a identidade é construída por meio da relação entre variação linguística e significado social. Nesse sentido, analisar a identidade como um componente estilístico ou o estilo como um componente identitário requer tanto (i) um olhar mais amplo para o contexto sócio-histórico e cultural das identidades e a relação entre elas e as ideologias nas quais estão envolvidas; quanto (ii) um olhar mais direcionado para o uso de variantes em relação aos tipos de interação em que ocorrem, já que é no interior desses cenários de interação que os padrões mais amplos de variação se acomodam. Tendo isso em vista, compreender a identidade como uma construção socioideológica é entender que ela "não é só local, tampouco global, nem micro nem macro, mas se estabelece através de uma relação dialética entre esses níveis” (KIESLING, 2013, p. 465) ${ }^{14}$.

Outra dimensão em que podemos pensar sobre as várias formas com as quais os indivíduos (re)constroem e mantêm suas identidades é em termos de afiliação a grupos, mais especificamente através das comunidades de práticas $(\mathrm{CP})$.

\subsection{A construção da identidade em comunidades de práticas}

Uma comunidade de práticas corresponde a um grupo de pessoas que compartilham comportamentos, pontos de vistas, opiniões, valores e preceitos, relações de poder e formas de se comunicar e que negociam e renegociam os significados de suas práticas estilísticas (ECKERT, 2006).

Para Scruton (1986 apud HALL, 2006), uma das principais motivações para formação de comunidades se dá pelo fato de que os sujeitos, ainda que se reconheçam como seres autônomos, buscam a todo momento sentir-se parte de algo mais amplo como um mecanismo de autoidentificação. Entretanto, o sentimento de unidade e plenitude trazido pelo pertencimento a um grupo não é suficiente para neutralizar a fragmentação e a multiplicidade do sujeito pós-moderno.

As práticas sociais coletivas que desencadeiam os processos de significação no inte-

\footnotetext{
${ }^{14}$ No original: "Identity construction is neither local nor global, micro nor macro, but represents a dialectic between them."
} 
rior das CPs podem muitas vezes levar a um entendimento de que as relações construídas nesses grupos são conduzidas por uma ideia de identidade mestra que unifica as identidades individuais de cada integrante (HALL, 2006). Contudo, ainda que os significados sejam convencionalizados com base na experiência e no conhecimento compartilhado de seus integrantes, a identidade, como um processo constitutivo que não finda em si, não se limita à plena afiliação a uma dada comunidade, mas sim "pelos esforços que trazem esses membros $[\ldots]$ nas relações uns com os outros [...], e pelas práticas que desenvolvem e transformam estes esforços” (ECKERT; MCCONNEL-GINET, 1995, p. 204). Nesse sentido, a noção de CP oferece uma nova lente para se entender o modo como os indivíduos constroem e mantêm suas identidades e relacionam modos de fala com modos de participação no mundo social (KIESLING, 2013). Tendo apresentado a base teórica que fundamenta a discussão sobre o significado social do uso variável de [-STE], apresentamos a seguir a descrição da comunidade em análise, locus desta pesquisa etnográfica.

\section{A comunidade Tal Qual Dublagens}

Um processo de observação e geração de dados em uma investigação etnográfica no ambiente virtual tem suas especificidades e suas limitações em relação ao fazer etnográfico tradicional, sobretudo quando se trata de realizar densas descrições sobre a comunidade observada.

No caso deste estudo, acreditamos que os principais desafios para traçar um perfil detalhado sobre o grupo em análise sejam o fato (i) de que se trata de uma comunidade com muitos membros (mais de 100 mil seguidores), o que dificulta uma observação mais profunda, principalmente porque chegar a um alto nível de detalhamento para esse quantitativo requer esforço e tempo de que não dispomos, e (ii) de que como não tivemos contato direto com cada um dos membros através de entrevistas virtuais ou on-line, por exemplo, as informações que temos sobre esses sujeitos foram coletadas através do próprio Instagram, o que nem sempre oferece profundos detalhamentos a respeito de suas características sociodemográficas.

Considerando essas limitações, apresentamos, de uma forma mais abrangente, uma descrição do perfil dos participantes e da dinâmica interacional da comunidade, ressaltando que interesses, opiniões ou valores são compartilhados entre essas pessoas, e que faz com que construam e integrem uma comunidade de práticas (CP).

$\mathrm{Na}$ época em que realizamos a etnografia (entre 2018 e 2020), a página contava com mais de 100 mil seguidores. É importante ressaltar que, apesar de considerarmos 
como membros da comunidade Tal Qual Dublagens no Instagram, esses mais de $100 \mathrm{mil}$ seguidores podem remeter a perfis de pessoas físicas, de lojas, empresas ou outras instituições; dentro dessa grande comunidade - que se forma em torno de um interesse comum geral, que parece ser a busca por entretenimento - há outras subcomunidades que parecem ser formadas por interesses mais complexos, algo que tende a criar conexões mais profundas entre os seguidores e o criador da página.

Em um primeiro momento, pela grande quantidade de seguidores naturais de Manaus, de outros municípios do Amazonas e do Pará, concluímos que essas conexões estariam atreladas majoritariamente ao compartilhamento de traços e laços territoriais, como uma espécie de identificação por pertencerem à mesma região, compartilharem de culturas semelhantes, o que iria, de certa forma, ao encontro da noção de comunidade de fala. No entanto, ao visitarmos o perfil de alguns dos seguidores mais participativos na página, verificamos que muitos deles são naturais de cidades de outras regiões do país - como o Rio de Janeiro, São Paulo e Porto Alegre, por exemplo - o que faz com que a hipótese sobre a conexão de um laço geográfico para a formação dessa comunidade não se sustente inteiramente, ainda que a página se mostre mais popular e conhecida entre os nortistas.

Como o aspecto da naturalidade parecia não ser suficiente para explicar a adesão de todos os membros, nos atentamos também ao fato de que a página conta com uma grande participação e engajamento de homens gays e mulheres heterossexuais que estão em contato com o universo gay ${ }^{15}$, o que seria mais um aspecto em comum com Gustavo, criador da página, isto é, a orientação à homossexualidade, ou no caso das mulheres heterossexuais, a simpatia aos homossexuais. A identificação gerada em torno do aspecto da orientação sexual, que pode desencadear tantas outras questões mais complexas, significa que esses sujeitos estão ligados por questões mais subjetivas e ideológicas, o que alude à noção de comunidade de práticas desenvolvida na subseção anterior. Esse nível de identificação parece ter levado ao estabelecimento e fortalecimento da comunidade na dimensão virtual e à adesão cada vez mais frequente de outros sujeitos que se identifiquem com esses aspectos identitários.

Considerando esses dois cenários, verificamos que a CP Tal Qual Dublagens é for-

\footnotetext{
${ }^{15}$ Essas mulheres podem ser caracterizadas pela expressão gay friendly, que remete à categoria de simpatizantes no antigo acrônimo GLS, substituído há alguns anos pela sigla LGBT (lésbicas, gays, bissexuais e travestis). Ao longo desta pesquisa, assumimos a sigla LGBT. Sabe-se que há outras formas de representação mais inclusivas, como LGBTQIA, LGBTT+, por exemplo, no entanto, como nosso objetivo não é discutir especificamente sobre isso, utilizamos a primeira por ser mais usualmente referenciada.
} 
mada por sujeitos que podem ou não ser amazonenses ou paraenses, podem ou não ser homossexuais. Isso quer dizer que essas características podem estar intercruzadas, por exemplo, o que nos dá algumas opções de perfis: (i) nortista gay (homem ou mulher); (ii) não nortista gay (homem ou mulher); (iii) nortista heterossexual (homem ou mulher) e (iv) não nortista heterossexual (homem ou mulher). ${ }^{16}$ É importante destacar que esses quatro perfis sociais não são dados de antemão pelo pesquisador. Eles são construídos/negociados durante a prática estilística desses sujeitos (seja o criador da página, seja seus seguidores), em que podem assumir diferentes posturas (stances), e são depreendidos na observação etnográfica.

Além desses dois principais aspectos envolvidos na formação dessa comunidade, os membros dessa CP, em geral, são indivíduos entre 15 e 50 anos de idade, com grau de escolaridade variando entre nível básico (ensino médio) e nível superior e de variadas ocupações, dentre as quais: estudante, artista, digital influencer/youtuber, vendedor, atendente, auxiliar administrativo, empresário, publicitário entre outras. ${ }^{17}$

Descrever o perfil da comunidade também implica levar em conta a maneira como os membros interagem entre si e o que está em jogo nessa interação. Nesse sentido, percebemos que a dinâmica interacional do grupo está relacionada com alguns fatores envolvidos na produção dos conteúdos da página.

Ao longo da nossa observação, verificamos que os principais conteúdos produzidos por Gustavo são as dublagens de vídeos e as postagens nas redes sociais. Em relação aos vídeos publicados no feed do Instagram, eles possuem curta duração (não podendo ultrapassar um minuto). Geralmente são recortes de um vídeo de dublagem mais extenso, que já foi postado no canal da página no Youtube e que trata de situações de briga entre vizinhos, briga entre gays e entre travestis, sobre a cidade de Manaus, sobre cenas de filmes e novelas e cenas de animais. Além das dublagens, Gustavo também publica outros tipos de vídeos, que diferentemente das dublagens, contam com a sua aparição, e retratam muitas das vezes aspectos mais pessoais de sua vida.

Já no que se refere às postagens, geralmente se referem a posts relacionados (i) às dublagens - em que os seguidores comentam e avaliam o vídeo -; (ii) a alguns aspectos

\footnotetext{
${ }^{16}$ De um modo geral, as opções nortista gay e não nortista gay parecem ser as mais frequentes, inclusive esses membros são os que mais interagem com a "titia Tal Qual” e com outros membros da página. Além desses perfis, entre as opções de heterossexuais, tanto nortista quanto não nortista, observamos uma participação mais recorrente das mulheres.

17 É importante esclarecer que essas e outras informações sobre os membros da CP em questão foram captadas a partir de comentários postados por esses sujeitos na página e também a partir de visitas no perfil pessoal de alguns seguidores. E, como ressaltamos anteriormente, nosso objetivo é apresentar uma descrição mais geral da comunidade e de seus participantes, já que algumas limitações, já mencionadas anteriormente, impossibilitam maiores detalhamentos.
} 
da vida pessoal de Gustavo - por exemplo: coisas do cotidiano como ir ao supermercado, sobre sua relação com seu marido, sobre sua família -; (iii) à divulgação de seus shows de stand-up comedy - ; e (iv) à publicidade de marcas e serviços.

Esse tipo de conteúdo mais pessoal só passa a ser incorporado nas publicações da página a partir de 2015, que remete ao período em que Gustavo revela sua identidade a seus seguidores (antes disso, as dublagens e as postagens são feitas de forma anônima). Pelo que observamos, por conta da revelação de sua identidade, a dinâmica interacional entre os seguidores passa a ser mais frequente e produtiva. Isso se verifica no mapeamento que fizemos, pois a quantidade de comentários, sobretudo os que contêm a forma [-STE], é muito maior no ano de 2015 do que em 2013 e 2014. Acreditamos que isso se deve ao fato de que a partir daquele momento os seguidores puderam associar um rosto, uma pessoa às dublagens e ao perfil virtual, o que parece ter tornado as interações mais intensas e frequentes. Provavelmente, por causa disso, o engajamento com a página aumentou nesse período, porque os sujeitos passaram a criar laços mais densos de identificação com a "titia Tal Qual", que a partir daquele momento tinha se tornado um personagem "real" e acessível.

Além da interação virtual, muitos dos membros, principalmente os residentes e/ou naturais de Manaus, conseguem ter esse contato mais direto e face a face com Gustavo através de encontros em lugares públicos da cidade ou em seus shows de stand-up comedy. Esses encontros acabam rendendo fotos e publicações nas redes sociais, configurando-se como um tipo de conteúdo bastante interativo e importante para a consolidação do grupo, haja vista que parece criar uma proximidade maior entre Gustavo e seus seguidores e dá a oportunidade de os outros membros, associados virtualmente a essa comunidade, se conhecerem pessoalmente.

Essa proximidade com Gustavo faz com que a página tenha altos níveis de interação e engajamento, porque as pessoas que escolhem fazer parte dessa comunidade não o fazem só porque querem se entreter com o conteúdo e a linguagem das dublagens, mas também porque se identificam com as caraterísticas e/ou traços socioculturais de Gustavo. E é nesse cenário que a CP Tal Qual Dublagens se estabelece.

A seguir, apresentamos e discutimos os resultados encontrados.

\section{Os significados sociais na variação de [-STE]}

Esta seção trata da análise e discussão dos resultados e está centrada na investigação dos significados sociais indexicalizados pelas formas alternativas de realização de [-STE]. Tendo isso em vista, desenvolvemos uma análise quanti-qualitativa a partir dos dados 
da amostra principal; de hipóteses baseadas em alguns estudos correlacionados com o fenômeno em questão; e da etnografia virtual realizada na $\mathrm{CP}$ analisada. A partir dos mapeamentos do referido morfema na página Tal Qual Dublagens, observamos cinco formas nas quais [-STE] pode ser realizado. São elas: -ste, -stes, -stis, -rte e -rtes, sendo -stes e -ste as mais recorrentes, com $61 \%$ e $24,5 \%$ respectivamente, como podemos observar na Tabela 1.

Tabela 1. Distribuição das formas de realização de [-STE]

\begin{tabular}{ccccccc}
\hline Formas & -ste & -stes & -stis & -rte & -rtes & Total \\
\hline $\mathrm{N}$ & 74 & 187 & 1 & 4 & 36 & 302 \\
$\%$ & 24,5 & 61,9 & 0,3 & 1,3 & 11,9 & 100
\end{tabular}

Fonte: Elaborado pela autora.

Em todos os dados analisados (302 ocorrências), qualquer uma das cinco formas alternativas de [-STE] estão agregadas a uma base verbal, mais especificamente após o tema (radical + vogal temática da conjugação correspondente) de um verbo; e associadas a P2 (tu), que funciona como sujeito. Além disso, parecem corresponder à categoria morfológica de sufixo flexional (desinência modo-temporal/DMT $\varnothing$ e desinência número-pessoal/DNP); e expressam o significado referencial de segunda pessoa do singular, desempenhando a função comunicativa de referência ao interlocutor (P2).

Além de todos os traços gramaticais envolvidos, o emprego de [-STE], particularmente na forma -ste, sinaliza uma situação de marcação de concordância canônica, que por si só já carrega valores sociais e estilísticos, como por exemplo: alta escolaridade, prestígio e formalidade, valores esses que remetem a um dos significados sociais indexicalizados pelo morfema, que denominamos aqui como significado de identidade macrossociológica ${ }^{18}$.

Somado a isso, os estudos de Scherre et al. (2015) e Babilônia e Martins (2014) caracterizam o uso de [-STE], associado a P2 (tu), como um dos seis subsistemas pronominais de segunda pessoa característico de algumas regiões do país, como a Região Norte, por exemplo, mais especificamente de municípios do estado do Amazonas, como Manaus - de onde uma parcela significativa dos membros da CP em análise, inclusive o criador da página Tal Qual Dublagens, são naturais.

Diante disso, em termos diatópicos, o uso de [-STE] e, potencialmente, de qual- 
quer uma de suas formas de realização, parece veicular também um valor sociolinguístico que distingue uma região da outra, o que significa que, concomitantemente aos traços de significado de identidade macrossociológica mencionados acima, o uso do morfema carrega também um traço constitutivo de significado identitário regional. Nessas condições, como a CP em questão, em certa medida, integra essa comunidade regional global, esse significado também é mantido na comunidade local, a CP Tal Qual Dublagens.

Outro resultado importante para esta análise está no estudo de Barroso (2017), que identifica o morfema -te (que se refere a [-STE]) como uma das sete categorias que compõem o dialeto bajubá/pajubá utilizado pela comunidade LGBT, sobretudo da cidade de Manaus. Com base nisso e considerando que alguns membros dessa comunidade também podem fazer parte da comunidade Tal Qual Dublagens, chegamos ao entendimento de que o uso de [-STE] na amostra analisada, por remeter a uma característica linguística da comunidade LGBT, pode ser entendido como um traço indexicalizador de mais um tipo de significado identitário, o que, nesse caso, denominamos como significado de identidade gay.

Além dos traços de significados indexicalizados por [-STE], mencionados acima, verificamos ainda que alguns traços fonético-fonológicos presentes nas quatro formas inovadoras (-stes, -stis, -rte e -rtes) do morfema em questão podem adicionar mais traços socioidentitários ao campo indexical de [-STE].

O primeiro caso está associado à presença de /s/ em posição de coda nas formas -stes, -stis e -rtes. Quanto a isso, aventamos a seguinte hipótese: no nosso entendimento, o acréscimo de /s/, sobretudo na forma -stes, pode ocorrer em razão de uma hipercorreção da forma -ste associada à segunda pessoa do singular (P2). Entretanto, acreditamos que essa não é a única explicação, até porque essa alteração fonética se apresenta nas outras duas formas.

Tomamos como base o estudo de Barbuio (2016), que evidencia a duração longa da fricativa /s/ em posição de coda final como um traço produzido por e associado a homens gays. Considerando isso, bem como o fato de que a maioria dos membros da Tal Qual Dublagens, incluindo o criador da página, possuem orientação sexual à homossexualidade $^{19}$ - o acréscimo de /s/ à -stes, -stis e -rtes pelos membros da Tal Qual Dublagens, em alguma medida, pode remeter a uma produção mais longa tanto do fonema em questão,

\footnotetext{
${ }^{19}$ No caso dos seguidores, a informação sobre a orientação sexual é captada indiretamente, através da observação da linguagem utilizada nos comentários. Em alguns casos (não temos quantitativo), observamos o perfil dos seguidores mais participativos e verificamos que são mulheres heterossexuais vinculadas ao universo gay e homens gays.
} 
quanto das formas em que ele é agregado ${ }^{20}$. E, nesse sentido, em alguma medida, isso se configuraria como mais um traço constitutivo de identidade gay. Desse modo, todas as formas em que o / s / é acrescido estariam retendo esse traço socioidentitário e o incorporando no campo indexical de [-STE].

O segundo caso de acréscimo de traço socioidentitário refere-se às formas que começam com -r (-rte e -rtes), mais especificamente no que se trata da troca de -s inicial por -r, que nesse caso é uma forma de representação ortográfica do processo fonológico de aspiração de /s/, o qual gera as formas aspiradas. Os trabalhos de Amaral (2016) e Vasconcellos (2017) têm evidenciado esse processo fonológico como uma importante marca da fala e também da escrita manauara e, tomando isso como base, compreendemos que o significado veiculado por esse traço fonético, grafado pelo -r inicial, seja mais um traço constitutivo do significado identitário regional atrelado ao uso de [-STE] na Tal Qual Dublagens. Nesse caso, como já mencionamos anteriormente, como a CP em questão, em alguma medida, integra a comunidade manauara, esse traço de significado também é compartilhado e expresso pelos membros da Tal Qual.

Além desses dois casos, parece haver um terceiro que não está relacionado a aspectos fonético-fonológicos, mas a um determinado contexto de uso: o uso de [-STE], e qualquer uma de suas formas alternativas, agregado a alguns verbos reconhecidos como itens do bajubá/pajubá (SILVA; PALHETA, 2008; BARROSO, 2017). Nossa interpretação é que quando as formas variantes de [-STE] são agregadas a esses itens, a expressão de identidade gay torna-se ainda mais saliente. No caso da amostra analisada, [-STE] é empregado aos verbos arrasar, lacrar e grelhar, que representam respectivamente 43,7\%, 4,3\% e 2,3\% das ocorrências. Esses três verbos são realizados pelas formas -ste, -stes, -rte e -rtes, que estão distribuídas como mostra a Tabela 2.

Tabela 2. Distribuição das formas alternativas de [-STE] agregadas a itens do bajubá

\begin{tabular}{|c|c|c|c|c|c|c|}
\hline Itens & & $-s t e$ & -stes & -rte & -rtes & Total \\
\hline \multirow{2}{*}{ Arrasar } & $\mathrm{N}$ & 32 & 86 & 4 & 10 & $132 / 302$ \\
& $\%$ & 24,3 & 65,2 & 3,0 & 7,5 & 43,7 \\
\hline \multirow{2}{*}{ Lacrar } & $\mathrm{N}$ & 1 & 9 & 0 & 3 & $13 / 302$ \\
& $\%$ & 7,7 & 69,2 & 0 & 23,1 & 4,3 \\
\hline
\end{tabular}

\footnotetext{
${ }^{20}$ A pronúncia alongada do /s/ nas formas de [-STE] é uma hipótese especulativa já que nenhuma análise foi realizada nesse sentido. Os dados de fala (através dos vídeos e dublagens) poderiam ter sido aferidos, mas a página foi removida do Instagram durante a realização desta pesquisa e, portanto, ficamos impossibilitados de testar essa hipótese.
} 


\begin{tabular}{|c|c|c|c|c|c|c|}
\hline \multirow{2}{*}{ Grelhar } & $\mathrm{N}$ & 4 & 3 & 0 & 0 & $7 / 302$ \\
& $\%$ & 57,2 & 42,8 & 0 & 0 & 2,3 \\
\hline
\end{tabular}

Fonte: Elaborado pela autora.

Analisando o conjunto de traços de significado descritos acima, compreendemos que eles transitam entre duas diferentes instâncias de significação: uma referencial ou semântico-pragmática, constituída pelos traços segunda pessoa do singular (P2 [tu]); referência ao interlocutor, e associado à categoria de sufixo flexional (DNP standard); e a outra de significado social associado a aspectos identitários, que se distribui em três diferentes camadas. A primeira camada refere-se a uma identidade macrossociológica - constituída pelos traços formalidade, prestígio e alta escolaridade -; a segunda, a uma identidade regional - constituída pelos traços P2 (tu) + marcação de concordância e aspiração de /s/ (troca de -s por -r) -; e a terceira, a uma identidade gay - constituída pelos traços morfema -te (referente a [-STE]); produção de /s/ em coda final; e morfema -te agregado a itens lexicais do bajubá/pajubá.

As ocorrências de [-STE] na amostra indicam que o item e, potencialmente, suas cinco formas alternativas de realização expressam concomitantemente essas duas instâncias. Considerando isso, chegamos ao entendimento de que a atuação simultânea dessas duas instâncias, mais especificamente, das camadas que constituem o significado social, resulta na expressão de um significado mais amplo, que carrega uma noção de identidade plural, que denominamos como significado de identidade de grupo social (referente à CP Tal Qual Dublagens). Contudo, apesar de a atuação conjunta dessas camadas indexicalizar a identidade de grupo social, isso se dá em diferentes graus de saliência. E é isso que verificamos adiante.

\section{1 [-STE] e a expressão de identidade de grupo social}

Antes da análise, julgamos importante descrever o procedimento analítico elaborado para a verificação dessa saliência.

Primeiramente, cada um dos traços constitutivos dos significados indexicalizados por

[-STE] foram distribuídos em quatro grupos: $1^{\circ}$ grupo: significado referencial; $2^{\circ}$ grupo: significado de identidade macrossociológica; $3^{\circ}$ grupo: significado de identidade regional; e $4^{\circ}$ grupo: significado de identidade gay; conforme mostra o Quadro 2.

Quadro 2. Significados indexicalizados por [-STE] e seus traços constitutivos 


\begin{tabular}{|c|c|c|c|}
\hline $\begin{array}{l}1^{\circ} \text { grupo: Significado } \\
\text { referencial }\end{array}$ & $\begin{array}{c}2^{\circ} \text { grupo: Significado de } \\
\text { identidade macrossocio- } \\
\text { lógica }\end{array}$ & $\begin{array}{l}3^{\circ} \text { grupo: Significado } \\
\text { de identidade regional }\end{array}$ & $\begin{array}{l}4^{\circ} \text { grupo: Significado } \\
\text { de identidade gay }\end{array}$ \\
\hline $\begin{array}{l}\text { Segunda pessoa do } \\
\text { singular; } \\
\text { Referência ao interlo- } \\
\text { cutor; } \\
\text { DNP standard. }\end{array}$ & $\begin{array}{l}\text { Alta escolaridade; } \\
\text { Prestígio; } \\
\text { Formalidade. }\end{array}$ & $\begin{array}{l}\text { P2 (tu) + concordância } \\
\text { canônica; } \\
\text { Aspiraçãa de /s/. }\end{array}$ & $\begin{array}{l}\text { Produção de /s/ em } \\
\text { coda final; } \\
\text { Morfema -te (referente } \\
\text { a [-STE]); } \\
\text { Morfema -te (referente } \\
\text { a [-STE]) agrega- } \\
\text { do a itens lexicais do } \\
\text { bajubá/pajubá. }\end{array}$ \\
\hline
\end{tabular}

Fonte: Elaborado pela autora.

Em seguida, foram atribuídos valores [+] ou [-], que indicam presença ou ausência de cada um desses traços, totalizando uma média de três valores para cada grupo. Considerando que no caso do $3^{\circ}$ grupo só há dois traços constitutivos, é atribuído dois valores ao traço de aspiração de /s/, por entendermos que tal traço expressa identidade regional de modo mais proeminente.

A partir disso, definimos, portanto, que a identificação da saliência em relação ao significado de identidade de grupo social (referente à CP Tal Qual Dublagens) se daria a partir da atribuição de graus escalares. Considerando que o $1^{\circ}$ e o $2^{\circ}$ grupos estão mais diretamente associados ao uso canônico de [-STE], enquanto o $3^{\circ}$ e o $4^{\circ}$ grupos remetem mais especificamente a características sociais e identitárias da CP em questão, percebemos que os dois últimos grupos têm um peso diferenciado no que se refere ao significado de identidade de grupo social. Tendo isso em vista, definimos o seguinte critério: quanto mais valores [-] nos $1^{\circ}$ e $2^{\circ}$ grupos e mais valores [+] nos $3^{\circ}$ e $4^{\circ}$ grupos, maior será a escala de saliência do significado de identidade de grupo social (referente à CP Tal Qual Dublagens). A atribuição de graus se dá de modo decrescente e está correlacionada com a quantidade de formas alternativas de [-STE]. No caso da base verbal padrão, temos cinco formas alternativas, portanto a escala vai do 1 ao 5 . A forma que receber a escala 1 indexicaliza o significado de grupo social de modo mais saliente e essa saliência vai sendo atenuada à medida que a escala vai diminuindo, podendo chegar à escala 5 , isto é, que sinaliza uma menor saliência. Em caso de as formas possuírem a mesma quantidade de valores, o maior grau de saliência será definido pelo grau de inovação da forma e não pela frequência na amostra.

Apresentados os esclarecimentos quanto ao procedimento analítico elaborado, verificamos a seguir qual das cinco formas de realização de [-STE] expressa identidade de grupo social de modo mais saliente. 
O Quadro 3 exibe os valores associados a cada forma de realização correspondente a cada grupo. A última linha desse quadro corresponde à atribuição do grau de saliência associado ao significado de identidade de grupo social (CP Tal Qual Dublagens).

Quadro 3 - Valores dos traços de significados indexicalizados pelas formas de realização de [-STE] e graus de saliência do significado de identidade de grupo social

\begin{tabular}{|c|c|c|c|c|c|}
\hline Grupos & -ste & -stes & -stis & -rte & -rtes \\
\hline $\begin{array}{l}1^{\circ} \text { grupo: Significado referencial } \\
\text { (i) Segunda pessoa do singular; } \\
\text { (ii) Referência ao interlocutor; } \\
\text { (iii) DNP standard. }\end{array}$ & {$[+++]$} & {$[++-]$} & {$[++-]$} & {$[++-]$} & {$[++-]$} \\
\hline $\begin{array}{l}2^{\circ} \text { grupo: Significado de identidade macros- } \\
\text { sociológica } \\
\text { (i) Alta escolaridade; } \\
\text { (ii) Prestígio; } \\
\text { (iii) Formalidade. }\end{array}$ & {$[++-]$} & {$[++-]$} & {$[++-]$} & {$[-+-]$} & {$[-+-]$} \\
\hline $\begin{array}{l}3^{\circ} \text { grupo: Significado de identidade regional } \\
\text { (i) P2 (tu) + concordância canônica; } \\
\text { (ii) Aspiração de /s/. }\end{array}$ & {$[+--]$} & {$[+--]$} & {$[+--]$} & {$[-++]$} & {$[-++]$} \\
\hline $\begin{array}{l}\mathbf{4}^{\circ} \text { grupo: Significado de identidade gay } \\
\text { (i) Produção de /s/ em coda final; } \\
\text { (ii) Morfema -te (referente a [-STE]); } \\
\text { (iii) Morfema -te (referente a [-STE]) agrega- } \\
\text { do a itens lexicais do bajubá/pajubá. }\end{array}$ & {$[-++]$} & {$[+++]$} & {$[++-]$} & {$[-++]$} & {$[+++]$} \\
\hline \multicolumn{6}{|c|}{ Graus de saliência } \\
\hline Significado de identidade de grupo social & 5 & 4 & 3 & 2 & 1 \\
\hline
\end{tabular}

Fonte: Elaborado pela autora.

No que se refere ao $1^{\circ}$ grupo, somente a forma -ste expressa o significado referencial de modo mais proeminente, haja vista que é a única que retém todos os traços constitutivos desse tipo de significado. As demais formas, embora estejam associadas à maioria dos traços - segunda pessoa do singular; referência ao interlocutor -, recebem um valor [-] porque correspondem, em diferentes graus, a formas inovadoras e, portanto, não remetem à DNP standard.

Em relação ao $2^{\circ}$ grupo, foram atribuídos a cada uma das cinco formas realizadas um valor [-] no que se refere ao traço formalidade, haja vista que o contexto de uso de [-STE], isto é, um site de rede social, como o Instagram, pode indicar uma situação de menor monitoramento e, portanto, um ambiente informal; e um valor [+] em relação ao traço prestígio. Embora tal traço esteja mais diretamente associado à forma canônica de $[-\mathrm{STE}]$ e, nesse sentido, somente -ste deveria receber um valor $[+]$, acredita-se que a 
realização de qualquer uma das formas inovadoras - o que no contexto de uma comunidade mais ampla poderia causar certo estigma - acaba carregando valor positivo dentro da comunidade de prática em análise, uma vez que tais formas estão associadas a traços identitários da comunidade.

Quanto aos outros dois traços constitutivos do significado de identidade macrossociológica, eles só deveriam ser atribuídos a -ste, haja vista que estão mais diretamente vinculados à forma canônica. No entanto, -stes e -stis também recebem um valor [+] quanto à alta escolaridade. Nesse caso, uma das hipóteses aventadas em relação a isso é de que o acréscimo de /s/ indica uma situação de hipercorreção associada a P2 e, possivelmente por causa disso, no que se trata desse significado, -stes e -stis continuam retendo o traço de alta escolaridade porque permanecem fortemente associados ao uso standard de [-STE]. Verifica-se, pois, que -ste, -stes e -stis são as formas mais proeminentes em relação ao significado de identidade macrossociológica. No caso de -rte e -rtes, como se trata de formas com um grau maior de inovação, elas parecem ser as menos proeminentes do referido significado.

Quanto ao $3^{\circ}$ grupo, verifica-se de um modo geral que o significado de identidade regional é o menos saliente em comparação aos demais grupos, porque os traços que o constituem estão diretamente relacionados a traços morfossintáticos e fonético-fonológicos presentes somente em algumas formas. Considerando isso, -ste retém o traço de $P 2$ + concordância canônica e, por isso, possui um valor [+]; as formas -stes e -stis, ainda que não sejam canônicas, remetem em diferentes graus ao uso standard e, por isso também recebem valor $[+]$ em relação a esse traço. No caso de -rte e -rtes, atribui-se dois valores [+] a cada uma, haja vista que estão associadas ao traço de aspiração de /s/.

Em relação ao $4^{\circ}$ grupo, por outro lado, o significado de identidade gay parece estar fortemente associado a [-STE] de um modo geral, e nesse sentido, suas formas de realização expressam tal significado com bastante proeminência. Considerando que um dos traços desse significado é o próprio item lexical analisado, todas as formas de realização de $[-S T E]$ recebem um valor $[+]$. No caso das formas -stes, -stis e -rtes, que estão associadas ao traço de produção de /s/ em coda final, é acrescido mais um valor [+] para cada. Além disso, todas as formas alternativas, com exceção de -stis, estão agregadas a itens lexicais do bajubá/pajubá, e, portanto, todas elas retêm mais um traço constitutivo desse significado. Diante disso e conforme o Quadro 3, as formas que terminam com /s/ expressam o significado de identidade gay com maior proeminência.

Considerando todos os valores atribuídos a cada conjunto de traços que consti- 
tuem as quatro camadas de significados veiculadas por [-STE], verifica-se que -rtes é a forma mais saliente no que se refere à expressão de identidade de grupo social (referente à CP Tal Qual Dublagens), uma vez que retém mais traços dos $3^{\circ}$ e $4^{\circ}$ grupos, os quais estão mais diretamente associados a características compartilhadas pelos membros da CP em análise.

A seguir, tecemos mais alguns comentários sobre os significados socioidentitários que compõem o campo indexical de [-STE], retomando alguns resultados e finalizando, por hora, a discussão.

\section{Finalizando a discussão ${ }^{21}$}

Ao longo desta investigação sobre o uso variável de [-STE] e os significados indexicalizados pelo referido morfema, verificamos que cada uma das cinco formas alternativas de realização de [-STE] expressa em maior ou menor saliência quatro camadas de significação, as quais constituem o significado de identidade de grupo social (referente à CP Tal Qual Dublagens) potencialmente veiculado por [-STE]. Mais especificamente no que se refere às três camadas de significados socioidentitários, é importante destacar que cada um está relacionado a diferentes noções de identidade.

O significado de identidade macrossociológica nos parece mais associado a uma noção de identidade em que os falantes são identificados a partir de características mais estáticas e que são comuns a todos os indivíduos, algo como uma identidade mais coletiva. Por exemplo, a pessoa que faz marcação de concordância canônica com P2 no PP é um falante que tem alta escolaridade e nos remete a uma situação de formalidade e consequentemente esse modo de uso é visto como prestigioso por membros de uma comunidade ampla (comunidade de fala, por exemplo). No entanto, essas informações não são capazes de evidenciar características mais complexas desse sujeito, justamente porque ele é observado apenas em relação às macroestruturas sociais em que se envolve.

Considerando os dados da amostra analisada e as hipóteses aventadas nas seções anteriores, compreendemos que o significado de identidade macrossociológica expresso por [-STE] está sensível a duas interpretações contextualmente estabelecidas pelos sujeitos (membros da CP em questão). Tais interpretações se dão a partir da relação dialética entre significados mais globais e mais locais (SILVERSTEIN, 2003). Desse modo, quando associado à forma canônica -ste, o uso de [-STE] expressa significados mais globais (associados a traços de alta escolaridade, formalidade e prestígio por exemplo) e, con-

${ }^{21}$ É importante esclarecer que alguns argumentos apresentados nessa seção são baseados em hipóteses interpretativas que precisam de resultados robustos de testes de percepção para serem validadas. 
sequentemente uma noção de identidade mais estática. Já quando as formas inovadoras (-stes, -stis, -rte e -rtes) são usadas, [-STE] tende a expressar significados localmente estabelecidos, em que o valor de prestígio associado predominantemente à forma -ste é ampliado também para as suas outras formas de realização, o que também ocorre com os outros níveis de identidade.

No caso da identidade regional, é possível pensar que esse tipo de significado apesar de ainda estar associado à identificação de características mais amplas e comuns a um número maior de indivíduos, como a questão da naturalidade, por exemplo - parece ganhar um grau a mais de significação social porque ele é expresso variavelmente dentro de um grupo específico, que tem objetivos, valores, opiniões em comum, no caso, a CP Tal Qual Dublagens. E, nesse sentido, as formas de realização que carregam traços constitutivos de identidade regional (como -ste, -rte e -rtes) acabam ganhando valor positivo pelos membros da comunidade, adquirindo prestígio encoberto. Pode-se dizer, pois, que a noção de identidade envolvida nesse tipo de significado remete a uma identificação que se dá a partir de aspectos mais subjetivos dos sujeitos, que se situa no escopo de algo mais local e menos global (SCHILLING, 2013).

Entretanto tal significado acaba sendo menos proeminente que a expressão de identidade gay, possivelmente porque nem todos os membros da CP em questão possuem a naturalidade manauara, e, portanto, podem não compartilhar os mesmos traços sociolinguísticos. E mesmo que todos fossem manauaras ou da Região Norte em geral, a regionalidade sugere um nível de identificação baseada no lugar de nascimento e/ou moradia, e tal aspecto parece não ser suficiente para a manutenção de relações sociais e formação de comunidades na dimensão online (WELLMANN, 2000).

No último caso, da identidade gay, como se trata de um nível mais complexo de identificação, haja vista que está mais relacionada a características mais subjetivas e ideológicas dos sujeitos, acredita-se que ela é capaz de formar e consolidar relações sociais mais significativas e, por isso, a expectativa é que cada vez mais os signos utilizados na $\mathrm{CP}$ em questão indexicalizem esse tipo de significado identitário, indicando, portanto, como categorias microssociais de identificação podem ser expressas a partir de fenômenos linguísticos variáveis (SILVERSTEIN, 2003). Um indicativo disso é o fato de que, ao longo dos quatro anos em que os dados foram produzidos (2013, 2014, 2015 e 2018), a forma -rtes, a que expressa de modo mais saliente o significado de grupo social aqui analisado, tem sido cada vez mais utilizada pelos membros da comunidade, o que nos leva a entender que os significados sociais vinculados a essa forma possam estar se tornando mais evidentes, levando-os a serem convencionalizados na comunidade. Contudo, apesar 
de -rtes apresentar essa inclinação gradativa a uma maior produtividade, é preciso levar em consideração que -stes, que em certa medida remete à variante standard, também é bastante utilizada, o que parece indicar que os significados sociais indexicalizados por [-STE] são fortemente expressos por essa forma.

Nesse grau de identificação, a formação de comunidades não se dá simplesmente porque os sujeitos têm algumas características em comum, por exemplo, ou possuem o mesmo grau de escolaridade ou porque são da mesma cidade. A comunidade se estabelece porque os sujeitos querem se associar; se afiliar e querem pertencer a esse grupo social porque se identificam uns com os outros em um nível mais complexo.

No caso da CP Tal Qual Dublagens, através da etnografia virtual realizada, observamos que o significado de identidade gay indexicalizado por [-STE] parece ser expresso de modo proeminente tanto para quem faz parte da comunidade - e, nesse caso, inclua-se a CP analisada e a comunidade LGBT -, quanto para não membros. Tal proeminência sugere que os traços constitutivos desse significado (morfema -te; produção de /s/ em coda final e morfema -te agregado a itens lexicais do bajubá/pajubá) estão em um alto nível de consciência desses sujeitos mesmo quando [-STE] é usado na forma canônica. E isso possivelmente ocorra porque esses sujeitos, principalmente aqueles que se afiliam tanto à CP Tal Qual Dublagens, quanto à comunidade LGBT, são responsáveis pela construção e estabelecimento desse significado em ambas as comunidades.

Para finalizar, é importante deixar claro que as discussões sobre o objeto desta pesquisa não se esgotam aqui. Muitas outras questões poderiam ter sido melhor exploradas - como, por exemplo, as diferentes situações de interação entre os membros da CP; o processo de construção de personae dos sujeitos que se afiliam a essa comunidade; a elaboração e aplicação de testes de atitude e percepção, entre muitos outros - se não fossem as limitações de tempo e de espaço (extensão da pesquisa). Tais questões fazem parte dos nossos interesses, os quais deixamos como embrião de encaminhamentos para pesquisas futuras.

\section{Referências}

AMARAL, K. O. do. Enfraquecimento das fricativas na fala manaura retratado na página Tal Qual Dublagens. 2016. Trabalho de Conclusão de Curso (Curso de Letras). Universidade do Estado do Amazonas, 2016.

AMARAL, K. O. do. Emergência de usos linguísticos inovadores em comunidades de práticas: o caso de [-STE] na página Tal Qual Dublagens. Working Papers em Linguística. Gramática do uso, v.21, n. 1, p. 168-196, 2020a.

AMARAL, K. O. do. Emergência de usos, variação e identidade: o caso de [-STE] na página 
Tal Qual Dublagens. 2020. 257 f. Dissertação [Mestrado em Linguística] - Programa de Pós-Graduação em Linguística, Universidade Federal de Santa Catarina, Florianópolis, 2020b.

BABILÔNIA, L.; MARTINS, S. A influência dos fatores sociais dos pronomes tu/você na fala manauara. Revista Guavira Letras. Três Lagoas, v. 13, p. 46-60, 2015.

BARBUIO, E. Percepção da orientação sexual de homens gays e heterossexuais por meio de características acústicas da fala. 2016. 137 f. Tese (Doutorado em Linguística). Programa de Pós-Graduação em Linguística (CCHLA/UFPB), João Pessoa, 2016.

BARROSO, R. Pajubá: o código linguístico da comunidade LGBT.2017.153f. Dissertação (Mestrado em Letras e Artes). Universidade do Estado do Amazonas. Manaus, 2017.

BLOMMAERT, J. Discourse: A Critical Introduction. Cambridge: Cambridge University Press (Key Topics in Sociolinguistics), 2005.

BRUBAKER, R, COOPER, F. Beyond "identity". Theory and Society 29. p. 1-47, 2000.

COUPLAND, N. The Sociolinguistics of Style. In: MESTHRIE, R. (Ed.). The Cambridge Handbook of Sociolinguistics. Cambridge: CUP, p. 138-156, 2011.

ECKERT, P.; MCCONNELL-GINET, S. Constructing meaning, constructing selves: Snapshots of language, gender and class from Belten High. In Kira Hall \& Mary Bucholtz (Ed.), Gender Articulated: Language and the socially constructed self. London: Routledge, 1995. p. 459-507.

ECKERT, P. Linguistic variation as social practice. Oxford: Blackwell, 2000.

ECKERT, P. Variation, convention, and social meaning. Paper presented at the Annual Meeting of the Linguistic Society of America. Oakland, 2005.

ECKERT, P. Communities of Practice. In: BROWN, K.; ANDERSON, H. (Ed.) Encyclopedia of Language and Linguistics, V. 2, Oxford, Elsevier, p.683-685, 2006.

ECKERT, P. Variation and the indexical field. Journal of Sociolinguistics, v. 12, n. 4, p. 453476, 2008.

ECKERT, P. Three waves of variation study: the emergence of meaning in the study of sociolinguistic variation. Annual Review of Anthropology, n. 41, p. 87-100, 2012.

ECKERT, P. Third wave variationism. 2016. Disponível em: http://www. oxfordhandbooks.com/view/10.1093/oxfordhb/9780199935345.001.0001/ oxfordhb9780199935345-e-27.

ECKERT, P. Meaning and linguistic variation: The third wave in sociolinguistics. Cambridge: Cambridge University Press, 2018.

HALL, S. A identidade cultural na pós-modernidade. Tradução de Tomaz Tadeu da Silva e Guarareira Lopes Louro. 10 ed. Rio de Janeiro: DP \& A, 2006.

HINE, C. Virtual Ethnography. London: SAGE Publications, 2000.

IRVINE, J. Style as distinctiveness: The culture and ideology of linguistic differentiation. In: ECKERT, P.; RICKFORD, J. (Ed.). Stylistic variation in language. Cambridge, UK: 
Cambridge University Press, p. 21-43, 2001.

IRVINE, J; GAL, S. Language ideology and linguistic differentiation. In: KROSKRITY, P. V. (Ed.). Regime of language: Ideologies, polities, and identities. Santa Fe: School of American Research Press, p. 35-84, 2000.

JAFFE, A. Stance: Sociolinguistic perspectives. Oxford Studies in Sociolinguistics. Oxford: Oxford University Press, - Volume 46 Issue 2, p. vii+261, 2009.

JUNG, C. G. Memórias, Sonhos e Reflexões. Reunidas e editadas por Aniela Jaffé. Rio de Janeiro: Nova Fronteira, 1975.

KIESLING, S. F. Constructing Identity. In: CHAMBERS, J. K.;TRUDGILL, P; SCHILLING, N. (Ed.). The Handbook of Language Variation and Change. 2. ed. Oxford, U.K.: Blackwell, p. 448-467, 2013.

LABOV, W. The social stratification of English in New York City. Washington, DC: Center for Applied Linguistics, 1966.

LABOV, W. Padrões sociolinguísticos. São Paulo: Parábola Editorial, 2008 [1972].

MARTINS, S; MARTINS, V. Particularidades do uso dos pronomes de segunda pessoa no falar do manauara: um estudo no panorama da variação pronominal do português do Brasil. InterDISCIPLINARY Journal of Portuguese Diaspora Studies, V. 3.1, p. 177-195, 2014.

SCHERRE, M; DIAS, E. P; ANDRADE, C; MARTINS, G. F. Variação dos pronomes Tu e você. In: MARTINS, M. A; ABRAÇADO, J. (Org.) Mapeamento sociolinguístico do português brasileiro. São Paulo: Contexto, p. 133-172, 2015.

SCHILLING, N. Investigating stylistic variation. In: CHAMBERS, J. K., TRUDGILL, P.; SCHILLING, N. (Ed.). The handbook of language variation and change. 2. ed. Malden: Blackwell, 2013, p. 327-349.

SILVA FILHO, M. R; PALHETA, S. P. Ser ou não ser? Os gays em questão: uma leitura antropológica das gírias utilizadas pelos homossexuais em Belém-PA. In: CD Virtual da 26a RBA, Porto Seguro-BA, 2008.

SILVERSTEIN, M. Indexical order and dialectics of sociolinguistic life. Language \& communication, University of Chicago, n.23, p.193-229, 2003.

SILVERSTEIN, M. Pragmatic Indexing. In: MEY, J. L. Concise Encyclopedia of Pragmatics. London: Elsevier, p. 756-759, 2009.

STETS, J. E.; BURKE, P. J. Identity Theory and Social Identity Theory. Social Psychology Quarterly, 63, p. 224-237, 2000.

TARALLO, F. A pesquisa sociolingüística. 2. ed. São Paulo: Ática, 1986.

VASCONCELLOS, S. A interferência dialetal na representação gráfica de fricativas na escrita de manauaras. 2017. 24 f. Trabalho de Conclusão de Curso. Universidade do Estado do Amazonas, Manaus, 2017.

WELLMANN, B. 'Physical Place and Cyber-Place: The rise of Networked Individualism'. 
Paper presented to Community Informatics: Connecting communities through the web. University of Teeside, 2000.

Data de submissão: 30/08/2020

Data de aceite: $25 / 10 / 2020$

(C) $(1) \Theta$ 